Pacific Journal of Mathematics

ON THE CONTINUOUS IMAGE OF A SINGULAR CHAIN 


\title{
ON THE CONTINUOUS IMAGE OF A SINGULAR CHAIN COMPLEX
}

\author{
GLen E. BREDON
}

\begin{abstract}
A continuous surjection $\pi: X \rightarrow Y$ between topological spaces is called "ductile" if, for each $y \in Y$ and neighborhood $U$ of $y$ there is a neighborhood $V$ of $y$ which contracts to $y$ through $U$ in such a way that this contraction can be covered by a homotopy of $\pi^{-1}(V)$. It is shown, in this note, that if $\pi: X \rightarrow Y$ is ductile and $Y$ is paracompact then the inclusion of the image $\pi_{*} C_{*}(X)$ of the singular chain complex of $X$ in the singular chain complex $C_{*}(Y)$ of $Y$ induces an isomorphism in homology. Thus $H_{*}(Y)$ can be computed from those singular simplices of $Y$ which are images of singular simplices of $X$.
\end{abstract}

This result does not hold, in general, when $\pi$ is not ductile. This question was brought to our attention (for a specific case) by Klingenberg who plans to use our result in a study of geodesics on a Riemannian manifold. We shall now rephrase the condition that a map be ductile in a more convenient language.

Let $\mathscr{C}$ be the category whose objects are surjective maps $\pi: X \rightarrow Y$ between topological spaces and whose morphisms are commutative diagrams

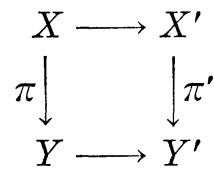

of continuous maps (where $\pi, \pi^{\prime} \in \mathscr{M} /$ ). This contains an analogue of homotopy, that is a commutative diagram

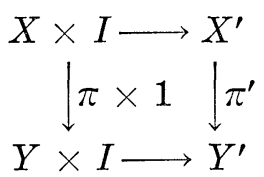

For $\pi: X \rightarrow Y$ and $A \subset Y$ we let $\pi_{A}$ denote the restriction $\pi^{-1}(A) \rightarrow A$ of $\pi$.

We will say that $\pi: X \rightarrow Y$ (in $\mathscr{C l}$ ) is ductile if, for each point $y \in Y$ and neighborhood $U$ of $y$, there is a neighborhood $V$ of $y$ with $V \subset U$ such that the inclusion $\pi_{V} \rightarrow \pi_{U}$ is homotopic (in $\mathscr{C}$ ) to a map into $\pi_{\{y\}}$. (Thus $V$ contracts, through $U$, to $\{y\}$ and this contraction is covered by a homotopy of $\pi^{-1}(V)$.)

Received September 22, 1964. This research was supported by NSF grant GP-1610. 
Most nice mappings are ductile. The following are all examples of ductile maps :

(a) Simplicial maps.

(b) Let $A \subset X$ both be $A N R$ 's (compact metric) and $\pi$ the map of identifying $A$ to a point.

(c) $Y=Y_{1} \cup Y_{2}$ where $Y_{1}, Y_{2} Y_{1} \cap Y_{2}$ are $A N R ' s, X=Y_{1}+Y_{2}$ (disjoint union) and where $\pi$ is the natural map.

(d) $\pi$ is the map of a differentiable manifold $X$ onto its orbit space under some compact Lie group acting differentiably on $X$ (see [1, Chapter VIII, 3.8]). According to Smale this also holds when $X$ is an infinite dimensional manifold.

(e) Let $M$ be a compact Riemannian manifold and $X$ the space of mappings $S^{1} \rightarrow M$ in the uniform metric. Regarding $S^{1}$ as the unit circle in the complex plane, $S^{1}$ acts on $X$ by $(z f)\left(z^{\prime}\right)=f\left(z z^{\prime}\right)$. Let $Y$ be the orbit space of this action. According to Svarc [4], this is ductile. According to Smale it falls under the infinite dimensional case of example $(d)$. It is this example that Klingenberg uses in studying geodesics on $M$.

THEOREM. Let $\pi$ be a ductile map of the space $X$ onto the paracompact space $Y$. Then the inclusion $\pi_{*} C_{*}(X) \subset C_{*}(Y)$ of chain complexes induces an isomorphism in homology.

For the proof, it is convenient to introduce some notation. For $\pi: X \rightarrow Y$ in $\mathscr{L}$, let $C_{*}(\pi)=\pi^{*} C_{*}(X), H_{p}(\pi)=H_{p}\left(C_{*}(\pi)\right), C^{*}(\pi)=$ $\operatorname{Hom}\left(C_{*}(\pi), Z\right)$, and $H^{p}(\pi)=H^{p}\left(C^{*}(\pi)\right)$. These are functors on $\mathscr{M}$. It is clear that homotopies in $\mathscr{C}$ induce chain homotopies, and therefore that homotopic maps $\pi \rightarrow \pi^{\prime}$ induce identical homomorphisms

$$
H_{p}(\pi) \rightarrow H_{p}\left(\pi^{\prime}\right) \text { and } H^{p}\left(\pi^{\prime}\right) \rightarrow H^{p}(\pi) \text {. }
$$

Note that, as a subcomplex of $C_{*}(Y), C_{*}(\pi)$ admits the operation of subdivision, and that standard methods show that this operation induces an isomorphism in homology.

Also note that if $\pi$ is ductile, then, with $y \in V \subset U$ as in the definition of ductile, the restriction $H^{p}\left(\pi_{\sigma}\right) \rightarrow H^{p}\left(\pi_{V}\right)$ factors through $H^{p}\left(\pi_{\{y\}}\right)=H^{p}(y)$ and hence is trivial for $p \neq 0$ and has image $Z$ for $p=0 . \quad\left(H^{p}(\pi) \rightarrow H^{p}\left(\pi_{\{y\}}\right)\right.$ is clearly surjective). Thus, when $\pi$ is ductile, the natural map

$$
\lim _{\rightarrow} H^{p}\left(\pi_{U}\right) \rightarrow H^{p}\left(\pi_{\{y\}}\right)=H^{p}(y)=\left\{\begin{aligned}
Z, & p=0 \\
0, & p \neq 0
\end{aligned}\right.
$$

is an isomorphism, where $U$ ranges over the neighborhoods of $y$. Now, for $\pi: X \rightarrow Y$ fixed, let $S^{*}$ be the (differential) presheaf on 
$Y$ defined by $S^{*}(U)=C^{*}\left(\pi_{U}\right)=\operatorname{Hom}\left(\pi_{*} C_{*}\left(\pi^{-1}(U)\right), Z\right) . \quad S^{*}$ clearly satisfies the axiom (F2) of Godement [2]. Let $\mathscr{S}^{*}$ be the sheaf generated by $S^{*}$. The kernel $S_{0}^{*}(Y)$ of the natural map $C^{*}(\pi)=$ $S^{*}(Y) \rightarrow \mathscr{S}^{*}(Y)$ consists of those cochains with empty support (that is, which vanish on "small" simplices of $\left.C_{*}(\pi)\right)$.

\section{LEMMA。 $H^{*}\left(S_{0}^{*}(Y)\right)=0$ 。}

Proof. For an open covering $\mathfrak{U}$ of $Y$ let $C_{*}^{\mathfrak{l l}}(\pi)$ be the subcomplex of $C_{*}(\pi)$ generated by those singular simplices which are contained in some member of $\mathfrak{u}$. A standard argument using subdivision shows that $H_{*}\left(C_{*}^{\mathfrak{l}}(\pi)\right) \rightarrow H_{*}\left(C_{*}(\pi)\right)$ is an isomorphism. If $C_{\mathfrak{1}}^{*}(\pi)=\operatorname{Hom}\left(C_{*}^{\mathfrak{l}}(\pi)\right.$, $Z)$ it follows that $H^{*}\left(C^{*}(\pi)\right) \rightarrow H^{*}\left(C_{\mathfrak{1}}^{*}(\pi)\right)$ is an isomorphism. Thus if $K_{\mathfrak{l}}^{*}=\operatorname{ker}\left\{C^{*}(\pi) \rightarrow C_{\mathfrak{l}}^{*}(\pi)\right\}$ then $H^{*}\left(K_{\mathfrak{l}}^{*}\right)=0$. But clearly $S_{0}^{*}(Y)=$ $\bigcup_{\mathfrak{U}} K_{\mathfrak{l}}^{*}=\lim K_{\mathfrak{l}}^{*}$. Thus $H^{*}\left(S_{0}^{*}(Y)\right)=H^{*}\left(\lim K_{\mathfrak{l}}^{*}\right)=\lim H^{*}\left(K_{\mathfrak{n}}^{*}\right)=0$.

Now suppose that $Y$ is paracompact. Then by $[\overrightarrow{2} ; 3,9.1$, p. 159], the sequence

$$
0 \rightarrow S_{0}^{*}(Y) \rightarrow S^{*}(Y) \rightarrow \mathscr{S}^{*}(Y) \rightarrow 0
$$

is exact, so that $H^{*}(\pi)=H^{*}\left(S^{*}(Y)\right) \approx H^{*}\left(\mathscr{S}^{*}(Y)\right)$.

Since each $S^{p}$ is an $S^{0}$-module, it follows that each $\mathscr{S}^{p}$ is an $\mathscr{S}^{0}$-module. $\mathscr{S}^{0}$ is just the ordinary singular cochain sheaf of $Y$ in degree zero and hence it is flabby. Since $Y$ is paracompact it follows that each $\mathscr{S}^{p}$ is soft.

Let $\mathscr{L}^{*}\left(\mathscr{S}^{*}\right)$ be the derived sheaf of $\mathscr{S}^{*}$. By standard facts, the stalk of this sheaf at $y \in Y$ is $\mathscr{C}^{*}\left(\mathscr{S}^{*}\right)_{y}=\lim _{y \in U} H^{*}\left(S^{*}(U)\right)=\lim _{y \in U} H^{*}\left(\pi_{U}\right)$ ( $U$ ranging over the neighborhoods of $y$ ). We have seen that, when $\pi$ is ductile, this is identified with $H^{*}(y)$. Thus, when $\pi$ is ductile, $\mathscr{S}^{*}$ is a resolution of the constant sheaf $Z$.

If $\mathscr{C}^{*}$ is the ordinary singular sheaf of $Y$, the diagram

$$
\begin{aligned}
& H^{*}\left(C^{*}(Y)\right) \rightarrow H^{*}\left(S^{*}(Y)\right)=H^{*}\left(C^{*}(\pi)\right) \\
& \downarrow \\
& H^{*}\left(\mathscr{C}^{*}(Y) \rightarrow H^{*}\left(\mathscr{S}^{*}(Y)\right)\right.
\end{aligned}
$$

commutes (note that $\mathscr{C}^{*}=\mathscr{S}^{*}$ when $\pi$ is the identity). If $Y$ is paracompact, the vertical maps are isomorphisms and so is the lower map when $\pi$ is ductile (see $[2,4.6 .2, p .1781$ ).

We wish to obtain this isomorphism on the homology level. Note that $C_{*}(Y) / C_{*}(\pi)$ is a free chain complex (generated by those singular simplices not in the image of $\pi$ ). We wish to show that $H_{*}\left(C_{*}(Y) / C_{*}(\pi)\right)=0$, under the hypotheses of the theorem. We know that the cohomology of this chain complex is trivial. Thus, by the universal coefficient theorem, it suffices to show that, for any abelian 
group $A$, Hom $(A, Z)=0=\operatorname{Ext}(A, Z)$ implies that $A=0$. This is proved in [3, Theorem 8.5] and completes the proof of our theorem.

In conclusion we give an example of a map $\pi ; X \rightarrow Y$ which is not ductile even though each point $y \in Y$ has a neighborhood $U$ such that $\pi^{-1}(U)$ can be deformed into $\pi^{-1}(y)$. Indeed the conclusion of the theorem does not hold for this example.

Let $Y_{1}$ be the interval $[0,1]$ on the $x$-axis of the $x-y$ plane and for $n>1$ let $Y_{n}$ be the upper semicircle $(y \geqq 0)$ with radius $1 / n$ and center at $(1 / n, 0)$. Let $Y=\bigcup_{n=1}^{\infty} Y_{n}$ and let $X$ be the disjoint union of the $Y_{n}$ with $\pi: X \rightarrow Y$ the natural map.

\section{REFERENCES}

1. A. Borel, et al, Seminar on transformation groups, Annals of Math. Study 46 (1960).

2. R. Godement, Théorie des Faisceaux, Herman (1958).

3. R. J. Nunke, Modules of extensions over Dedekind rings, Illinois J. Math. 3 (1959), 222-241.

4. A. S. Švarc, The homologies of spaces of closed curves, Trudy Moskov Mat. Obsc. 9 (1960), 3-44.

UNIVERSITY OF CALIFORNIA, BERKELEY 


\title{
PACIFIC JOURNAL OF MATHEMATICS
}

\author{
EDITORS
}

\author{
H. SAmelson \\ Stanford University \\ Stanford, California \\ R. M. Blumenthal \\ University of Washington \\ Seattle, Washington 98105
}

\author{
J. DugundjI \\ University of Southern California \\ Los Angeles, California 90007
}

*Richard Arens

University of California

Los Angeles, California 90024

\section{ASSOCIATE EDITORS}
E. F. BECKENBACH
B. H. NeUmanN
F. WOLF
K. YoSIDA

\section{SUPPORTING INSTITUTIONS}

\author{
UNIVERSITY OF BRITISH COLUMBIA \\ CALIFORNIA INSTITUTE OF TECHNOLOGY \\ UNIVERSITY OF CALIFORNIA \\ MONTANA STATE UNIVERSITY \\ UNIVERSITY OF NEVADA \\ NEW MEXICO STATE UNIVERSITY \\ OREGON STATE UNIVERSITY \\ UNIVERSITY OF OREGON \\ OSAKA UNIVERSITY \\ UNIVERSITY OF SOUTHERN CALIFORNIA
}

\author{
STANFORD UNIVERSITY \\ UNIVERSITY OF TOKYO \\ UNIVERSITY OF UTAH \\ WASHINGTON STATE UNIVERSITY \\ UNIVERSITY OF WASHINGTON \\ * * * * \\ AMERICAN MATHEMATICAL SOCIETY \\ CALIFORNIA RESEARCH CORPORATION \\ SPACE TECHNOLOGY LABORATORIES \\ NAVAL ORDNANCE TEST STATION
}

Mathematical papers intended for publication in the Pacific Journal of Mathematics should by typewritten (double spaced). The first paragraph or two must be capable of being used separately as a synopsis of the entire paper. It should not contain references to the bibliography. No separate author's resumé is required. Manuscripts may be sent to any one of the four editors. All other communications to the editors should be addressed to the managing editor, Richard Arens, at the University of California, Los Angeles, California 90024.

50 reprints per author of each article are furnished free of charge; additional copies may be obtained at cost in multiples of 50 .

The Pacific Journal of Mathematics is published quarterly, in March, June, September, and December. Effective with Volume 13 the price per volume (4 numbers) is $\$ 18.00$; single issues, $\$ 5.00$. Special price for current issues to individual faculty members of supporting institutions and to individual members of the American Mathematical Society: $\$ 8.00$ per volume; single issues $\$ 2.50$. Back numbers are available.

Subscriptions, orders for back numbers, and changes of address should be sent to Pacific Journal of Mathematics, 103 Highland Boulevard, Berkeley 8, California.

Printed at Kokusai Bunken Insatsusha (International Academic Printing Co., Ltd.), No. 6, 2-chome, Fujimi-cho, Chiyoda-ku, Tokyo, Japan.

PUBLISHED BY PACIFIC JOURNAL OF MATHEMATICS, A NON-PROFIT CORPORATION

The Supporting Institutions listed above contribute to the cost of publication of this Journal, but they are not owners or publishers and have no responsibility for its content or policies.

* Basil Gordon, Acting Managing Editor until February 1, 1966. 


\section{Pacific Journal of Mathematics}

\section{Vol. 15, No. $4 \quad$ December, 1965}

Robert James Blattner, Group extension representations and the structure space ........... 1101

Glen Eugene Bredon, On the continuous image of a singular chain complex .............. 1115

David Hilding Carlson, On real eigenvalues of complex matrices .................... 1119

Hsin Chu, Fixed points in a transformation group ............................. 1131

Howard Benton Curtis, Jr., The uniformizing function for certain simply connected Riemann

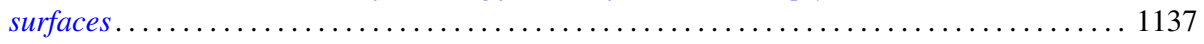

George Wesley Day, Free complete extensions of Boolean algebras................... 1145

Edward George Effros, The Borel space of von Neumann algebras on a separable Hilbert

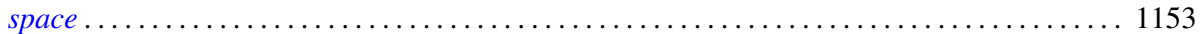

Michel Mendès France, $A$ set of nonnormal numbers ......................... 1165

Jack L. Goldberg, Polynomials orthogonal over a denumerable set ................ 1171

Frederick Paul Greenleaf, Norm decreasing homomorphisms of group algebras . . . . . . . . 1187

Fletcher Gross, The 2-length of a finite solvable group ........................ 1221

Kenneth Myron Hoffman and Arlan Bruce Ramsay, Algebras of bounded sequences ........ 1239

James Patrick Jans, Some aspects of torsion . . . . . . . . . . . . . . . . . . . . . . . 1249

Laura Ketchum Kodama, Boundary measures of analytic differentials and uniform

approximation on a Riemann surface ............................... 1261

Alan G. Konheim and Benjamin Weiss, Functions which operate on characteristic

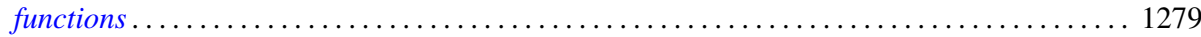

Ronald John Larsen, Almost invariant measures ............................ 1295

You-Feng Lin, Generalized character semigroups: The Schwarz decomposition ............ 1307

Justin Thomas Lloyd, Representations of lattice-ordered groups having a basis . . . . . . . . 1313

Thomas Graham McLaughlin, On relative coimmunity ....................... 1319

Mitsuru Nakai, $\Phi$-bounded harmonic functions and classification of Riemann surfaces ....... 1329

L. G. Novoa, On n-ordered sets and order completeness ..................... 1337

Fredos Papangelou, Some considerations on convergence in abelian lattice-groups . . . . . . . 1347

Frank Albert Raymond, Some remarks on the coefficients used in the theory of homology

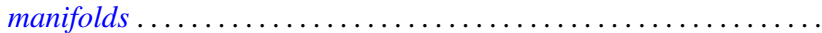

John R. Ringrose, On sub-algebras of a $C^{*}$-algebra .

Jack Max Robertson, Some topological properties of certain spaces of differentiable

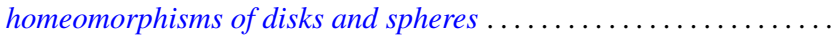

Zalman Rubinstein, Some results in the location of zeros of polynomials

Arthur Argyle Sagle, On simple algebras obtained from homogeneous general Lie triple systems. . . .

Hans Samelson, On small maps of manifolds ............................... 1401

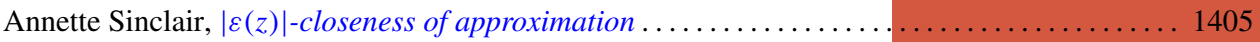

Edsel Ford Stiel, Isometric immersions of manifolds of nonnegative constant sectional curvature

Earl J. Taft, Invariant splitting in Jordan and alternative algebras ................. 1421

L. E. Ward, On a conjecture of R. J. Koch . . . . . . . . . . . . . . . . . . . . . . . . . . . 1429

Neil Marchand Wigley, Development of the mapping function at a corner . . . . . . . . . . 1435

Horace C. Wiser, Embedding a circle of trees in the plane ....................... 1463

Adil Mohamed Yaqub, Ring-logics and residue class rings . . . . . . . . . . . . . . . . 1465

John W. Lamperti and Patrick Colonel Suppes, Correction to: Chains of infinite order and their application to learning theory ........................................ 1471

Charles Vernon Coffman, Correction to: Non-linear differential equations on cones in Banach

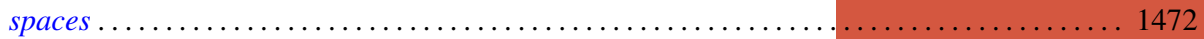

P. H. Doyle, III, Correction to: A sufficient condition that an $\operatorname{arc}$ in $S^{n}$ be cellular. . . . . . . . 1474

P. P. Saworotnow, Correction to: On continuity of multiplication in a complemented algebra 